Check for updates

Cite this: Mater. Adv., 2020, 1,1939

Received 23rd June 2020, Accepted 28th July 2020

DOI: 10.1039/d0ma00445f

rsc.li/materials-advances

\section{Development of ZnO@rGO nanocomposites for the enzyme free electrochemical detection of urea and glucose $\dagger$}

\author{
K. B. Babitha, ${ }^{a}$ P. S. Soorya, ${ }^{a}$ A. Peer Mohamed, ${ }^{a}$ R. B. Rakhi (D) ${ }^{a b}$ and \\ S. Ananthakumar*a
}

\begin{abstract}
Herein, we report a green synthetic strategy for the preparation of ZnOarGO nanocomposites. Bioinspired synthesis of $\mathrm{ZnO}$ nanoarchitectures has been done using a series of biotemplates such as dextrose, sucrose, soluble starch, and carboxy methyl cellulose. The as-prepared morphologically tuned $\mathrm{ZnO}$ nanoarchitectures are homogeneously distributed over the surface of rGO sheets, resulting in the formation of ZnO@rGO nanocomposites. For the first time, zinc (Zn) dust, a waste byproduct from industry (Binani Zinc Limited, Kerala, India), is employed for the chemical reduction of GO. ZnOarGO nanocomposite based nonenzymatic urea and glucose sensors have been developed over a glassy carbon electrode, and the electrochemical performance of the nanocomposite for the detection of urea and glucose are investigated. The biosensor electrode is sensitive to urea in the concentration range of $0.02 \times 10^{-3} \mathrm{mM}$ to $7.2 \times 10^{-3} \mathrm{mM}$ with a detection limit of $0.012 \mu \mathrm{M}$. When used for glucose detection, the linear range is $0.02 \times 10^{-3} \mathrm{mM}$ to $18 \times 10^{-3} \mathrm{mM}$, with a detection limit of $0.008 \mu \mathrm{M}$. The developed sensor exhibits an ultra-high sensitivity of $682.8 \mu \mathrm{A} \mathrm{mM} \mathrm{mM}^{-1} \mathrm{~cm}^{-2}$ towards urea and $481 \mu \mathrm{A} \mathrm{mM} \mathrm{mm}^{-1} \mathrm{~cm}^{-2}$ towards glucose.
\end{abstract}

\section{Introduction}

Urea is the most widely used fertilizer, and its production and consumption in India are about 23 and 31 million tonnes. Due to its higher solubility in water, a large amount of the applied urea may get dissolved in groundwater and leads to waterpollution. ${ }^{1}$ From a biological point of view, urea is the final product of protein degradation and nitrogen metabolism. The normal concentration of urea in blood serum is $2.5-7.5 \mathrm{mM}^{2}$ The higher or lower amount of urea in the body leads to several diseases such as renal failure, urinary tract obstruction, dehydration, shock burns, gastrointestinal bleeding, hepatic failure, nephritic syndrome, and cachexia. ${ }^{3,4}$ So the monitoring of the urea level has great significance in both environmental and clinical samples.

Glucose is the primary source of energy in the human body. ${ }^{5}$ The acceptable range of the blood glucose level in the human

\footnotetext{
${ }^{a}$ Functional Materials Section, Materials Science and Technology Division, CSIR-National Institute for Interdisciplinary Science and Technology, Industrial Estate P.O., Thiruvananthapuram 695019, Kerala, India. E-mail: ananthakumar70@gmail.com, ananthakumars@niist.res.in, rakhisarath@gmail.com, rakhiraghavanbaby@niist.res.in; Fax: +91 471 2491712; Tel: +914712515289

${ }^{b}$ Department of Physics, University of Kerala, Kariavattom P.O., Thiruvananthapuram 695581, Kerala, India

† Electronic supplementary information (ESI) available. See DOI: 10.1039/d0ma00445f
}

body is $\sim 3.9-6.2$ (empty stomach) or $\sim 3.9-7.8$ ( $2 \mathrm{~h}$ after food) mM. ${ }^{6}$ If the human body is unable to control the amount of glucose due to decreased insulin secretion, the condition results in diabetes mellitus. ${ }^{7}$ Furthermore, it leads to different health problems like cardiovascular, nervous, ocular, cerebral and peripheral vascular diseases, kidney failure, tissue damage, blindness, etc. ${ }^{5,8}$ Hence, quantitative monitoring of the blood glucose level is essential, to avoid the adverse effects of diabetes. ${ }^{5}$

A quantum of research studies has been conducted to develop an efficient and reliable method for urea and glucose sensing. The electrochemical sensing strategy has been considered as the most promising tool for urea and glucose detection. $^{9,10}$ Metal oxides such as $\mathrm{ZnO}, \mathrm{Fe}_{2} \mathrm{O}_{3}, \mathrm{CeO}_{2}, \mathrm{SnO}_{2}$, $\mathrm{Ag}_{2} \mathrm{O}, \mathrm{ZrO}_{2}, \mathrm{TiO}_{2}, \mathrm{Co}_{3} \mathrm{O}_{4}, \mathrm{NiO}, \mathrm{Cu}_{2} \mathrm{O}, \mathrm{MnO}_{2}, \mathrm{MgO}, \mathrm{RuO}_{2}$, and $\mathrm{Mn}_{3} \mathrm{O}_{4}$ have been extensively studied for electrochemical sensors. Among these, $\mathrm{ZnO}$ nanoparticles were most widely studied for electrochemical biosensing applications. In electrochemical sensors, nonenzymatic sensors are most popular because they can overcome the disadvantages of enzymatic sensors. ${ }^{11}$

Graphene-based nanomaterials are widely used in electrocatalytic sensing applications. rGO is found to be the most preferred sensor platform due to the following reasons: (1) rGO is electrically conductive compared to the non-conductive GO, (2) a large number of edges and defects facilitate electron 
transfer and (3) conductivity and surface functional groups could be tuned for the detection of specific chemical species. Different methods are reported for the preparation of rGO from GO. In 2010, X. Gao et al. showed that the deoxygenation of GO with hydrazine or heat treatment results in GGO. $^{12}$ In 2011, P. Cui et al. reported a new reducing system i.e., hydriodic acid with trifluoroacetic acid, which can chemically convert GO into rGO at subzero temperature (below $0{ }^{\circ} \mathrm{C}$ ) with mass production. ${ }^{13}$ In 2012, V. H. Pham et al. reported a simple and effective method to reduce the aqueous suspension of GO using nascent hydrogen generated in situ by the reaction between $\mathrm{Al}$ foil and $\mathrm{HCl}, \mathrm{Al}$ foil and $\mathrm{NaOH}$, and $\mathrm{Zn}$ powder and $\mathrm{NaOH} .{ }^{14}$ In 2012, O. Akhavan et al. reported a single-step green method for the reduction and functionalization of GO by glucose. ${ }^{15}$ In 2012 , R. S. Dey et al. demonstrated a facile route for the synthesis of rGO sheets by the chemical reduction of GO using $\mathrm{Zn}$ /acid solution at room temperature. ${ }^{16}$ To the best of our knowledge, no attempts were made to conduct the reduction of GO using waste materials.

The use of biomaterials as templates has become significant in the green synthesis of nanomaterials with controllable morphology. Biomaterials are cheap, economical, environmentally begin, and renewable. In the present work, $\mathrm{ZnO}$ nanoarchitectures with varied morphology were prepared via the biotemplate assisted microwave method. Here dextrose, sucrose, soluble starch, and carboxy methyl cellulose were used as biotemplates. At the same time, rGO was prepared by the chemical reduction of GO using nascent hydrogen. Zn dust, a waste material obtained from industry, was used for the generation of nascent hydrogen. It acts as a strong reducing agent. $\mathrm{ZnO}$ nanoarchitectures prepared with different biotemplates are attached on rGO via the microwave assisted ex situ technique, which results in ZnO@rGO nanocomposites. Structural and morphological studies were carried out, showing the homogeneous distribution of $\mathrm{ZnO}$ nanoarchitectures on rGO sheets. The as-prepared ZnO@rGO has been used for the nonenzymatic sensing of urea and glucose. Since the studies on nonenzymatic $\mathrm{ZnO}$ based glucose and urea sensors are rarely reported, the fabrication and performance of $\mathrm{ZnO@rGO} \mathrm{based} \mathrm{sensors} \mathrm{are}$ important. Similarly, the synergistic effect of both $\mathrm{ZnO}$ and $\mathrm{rGO}$ provides excellent sensing characteristics in the as-prepared nonenzymatic sensor.

\section{Experimental section}

\subsection{Materials}

Graphite (99.9\%), Nafion solution (5 wt\% in lower aliphatic alcohols and water contains $15-20 \%$ water) and potassium ferri cyanide $\left(\mathrm{C}_{6} \mathrm{~N}_{6} \mathrm{FeK}_{3}, 99.9 \%\right)$ were procured from Sigma Aldrich, Germany. Sodium nitrate $\left(\mathrm{NaNO}_{3}, 99.5 \%\right)$, potassium permanganate $\left(\mathrm{KMnO}_{4}, 99 \%\right)$, hydrogen peroxide $\left(\mathrm{H}_{2} \mathrm{O}_{2}, 99 \%\right)$, dextrose anhydrous (D-glucose anhydrous, $\mathrm{C}_{6} \mathrm{H}_{12} \mathrm{O}_{6}, 99 \%$ ), sucrose (saccharose, $\mathrm{C}_{12} \mathrm{H}_{22} \mathrm{O}_{11}, 99 \%$ ), and carboxy methyl cellulose sodium salt were obtained from $\mathrm{S}$. D. Fine Chemicals limited, India. Zinc nitrate hexahydrate $\left(\mathrm{Zn}\left(\mathrm{NO}_{3}\right)_{2} \cdot 6 \mathrm{H}_{2} \mathrm{O}, 99 \%\right)$, conc. sulphuric acid $\left(\mathrm{H}_{2} \mathrm{SO}_{4}, 99 \%\right)$ and soluble starch $\left(\left(\mathrm{C}_{6} \mathrm{H}_{10} \mathrm{O}_{5}\right)_{n}\right.$, 99\%) were supplied by Merck, India. Lithium hydroxide $(\mathrm{LiOH}$, 99\%) was purchased from SRL, India. Zn dust obtained from Binani Zinc Limited was used for the reduction of GO. All the reagents were used as received without any further purification.

\subsection{Preparation of GO}

GO has been prepared via Hummers' method. In a typical procedure $1 \mathrm{~g}$ graphite and $1 \mathrm{~g} \mathrm{NaNO}_{3}$ were dispersed in $50 \mathrm{~mL}$ conc. $\mathrm{H}_{2} \mathrm{SO}_{4}$ while keeping in an ice bath. $3 \mathrm{~g}$ of $\mathrm{KMnO}_{4}$ was added slowly to the reacting mixture and the reaction temperature was not allowed to increase to $20{ }^{\circ} \mathrm{C}$. The reaction mixture was then transferred to a water bath kept at a temperature of $35{ }^{\circ} \mathrm{C} .50 \mathrm{~mL}$ of distilled water was added to the system and the temperature raised to $98{ }^{\circ} \mathrm{C}$. It was followed with the addition of $150 \mathrm{~mL}$ of distilled water and $10 \mathrm{~mL}$ of $30 \% \mathrm{H}_{2} \mathrm{O}_{2}$. The oxidized graphite was then centrifuged and washed with double distilled water until the $\mathrm{pH}$ becomes 7 . Finally, on freeze drying graphene oxide with a fluffy nature was obtained..$^{17,18}$

\subsection{Preparation of rGO via nascent hydrogen chemical reduction}

In a typical procedure, $20 \mathrm{mg}$ of GO was dispersed in a $200 \mathrm{~mL}$ double distilled water using a probe sonicator. It was further treated with conc. $\mathrm{HCl}(1 \mathrm{M})$ followed by the slow addition of $\mathrm{Zn}$ dust ( $2 \mathrm{~g}$ ). The whole mixture was stirred overnight using a magnetic stirrer. The gradual change in the colour from orangebrown to black indicates the reduction of GO to rGO. The obtained rGO was then collected by centrifugation. Furthermore, it was washed three times with $0.1 \mathrm{M} \mathrm{HCl}$, followed by washing with double distilled water. After removing all impurities, the rGO nanosheets were freeze-dried. Illustration for the nascent hydrogen chemical reduction is shown in Fig. 1.

\subsection{Synthesis of $\mathrm{ZnO}$ nanoarchitectures via the biotemplate method}

ZnO nanoarchitectures were prepared via the biotemplate assisted microwave technique (Fig. 2, step 1). In a typical procedure, $0.3 \mathrm{M} \mathrm{Zn}\left(\mathrm{NO}_{3}\right)_{2} \cdot 9 \mathrm{H}_{2} \mathrm{O}$ was dissolved in $500 \mathrm{~mL}$ double-distilled water, and an appropriate amount of carbohydrate/cellulose was dispersed eventually by keeping the wt ratio of $\mathrm{Zn}\left(\mathrm{NO}_{3}\right)_{2} \cdot 9 \mathrm{H}_{2} \mathrm{O}$ and carbohydrate/cellulose as 1:1. Dextrose, sucrose, soluble starch, and carboxy methyl cellulose were used as structure-directing agents. The $\mathrm{pH}$ of the solution was adjusted with $10 \mathrm{wt} \% \mathrm{LiOH}$ solution. The obtained solution was kept in a microwave synthesis work station (Sineo MAS II) at $80{ }^{\circ} \mathrm{C}$ for $30 \mathrm{~min}(P=300 \mathrm{~W})$. The obtained powder was washed repeatedly with double distilled water to remove the impurities. The final product was dried in an oven at $50{ }^{\circ} \mathrm{C}$. The obtained ZnO samples were denoted as ZD, ZS, ZSs, and ZC, respectively.

\subsection{Preparation of $\mathrm{ZnO@1rGO} \mathrm{nanocomposites}$}

In a typical synthesis of the nanocomposites, $0.0025 \mathrm{~g}$ of $\mathrm{rGO}$ (1 wt\%) was uniformly dispersed in $30 \mathrm{~mL}$ of DMF with the aid 
GO dispersed in water

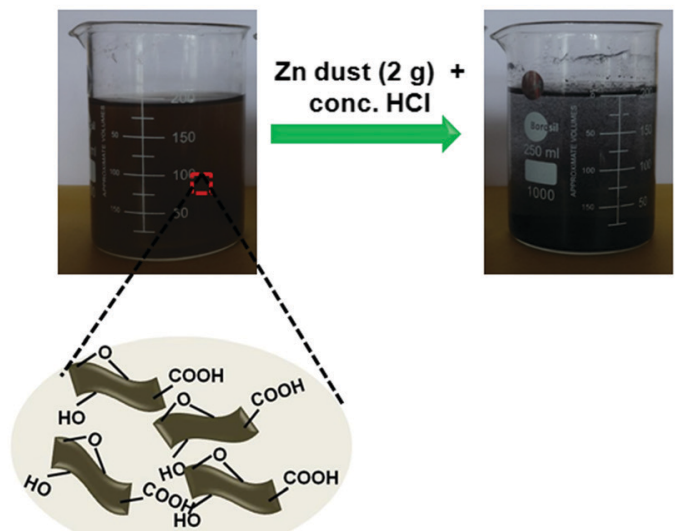

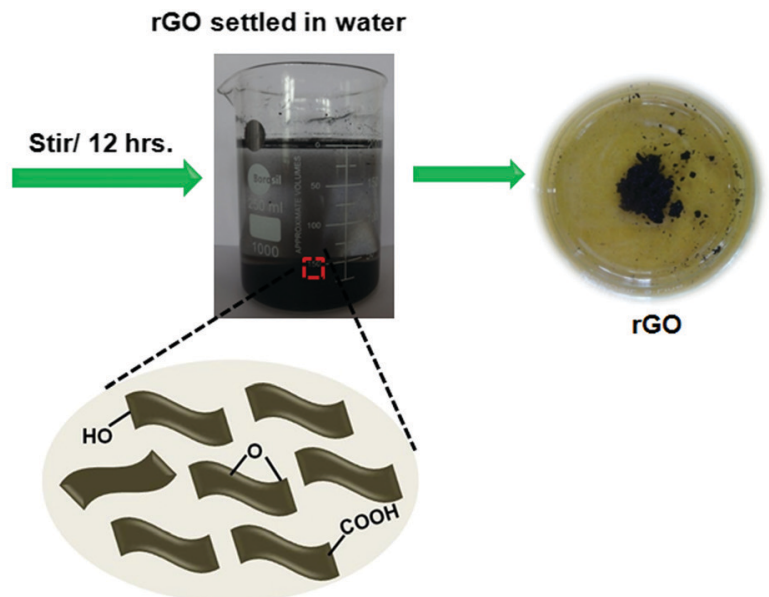

Fig. 1 Illustration of the $\mathrm{Zn}$ mediated nascent hydrogen chemical reduction of $\mathrm{GO}$ in the presence of conc. $\mathrm{HCl}$.
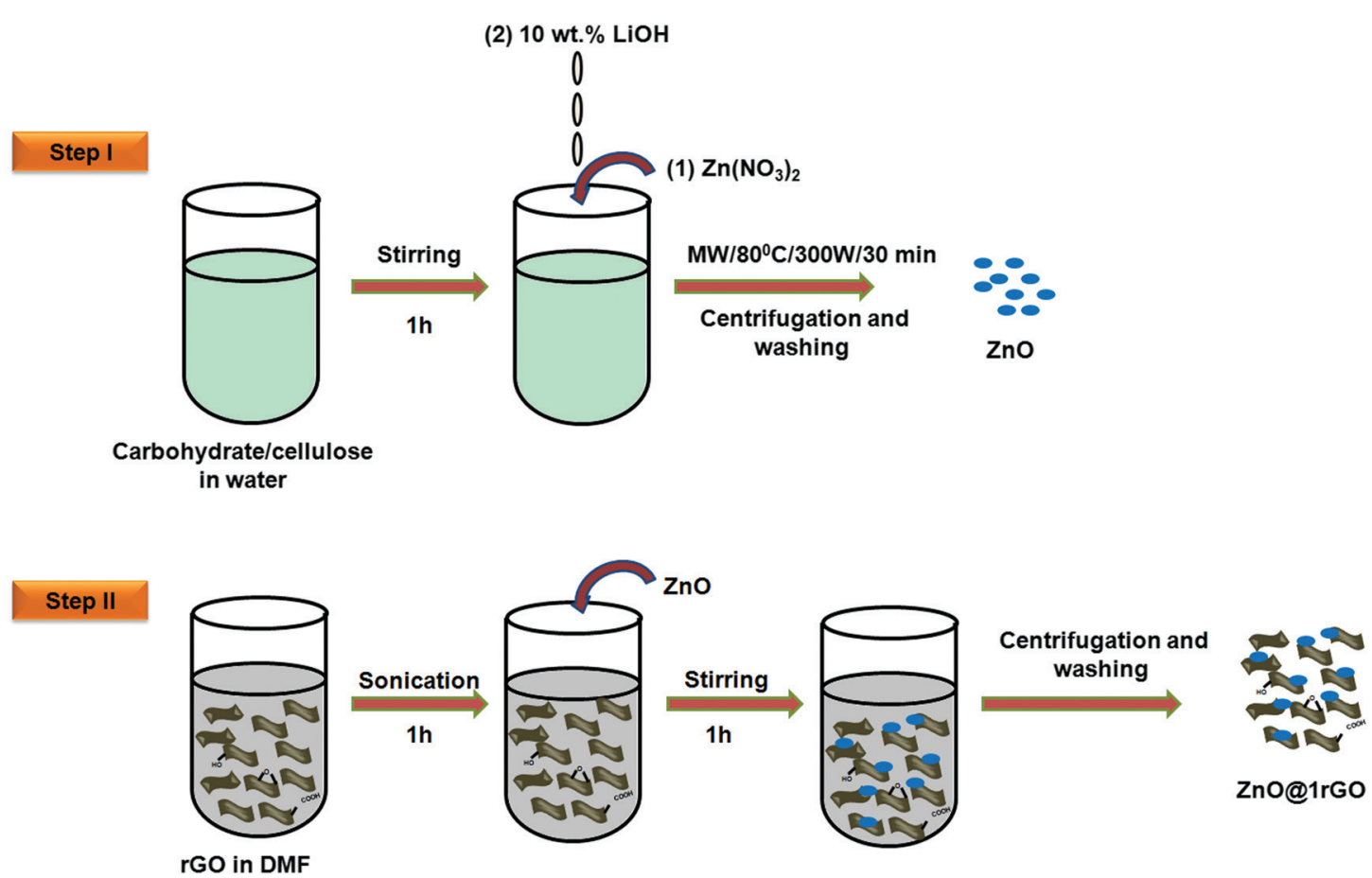

Fig. 2 Schematic illustration showing the synthetic procedure of $\mathrm{ZnO}$ and $\mathrm{ZnO} @ 1 \mathrm{rGO}$.

of ultrasonication for $1 \mathrm{~h}$ to obtain a uniform suspension of rGO. Then $0.2475 \mathrm{~g}$ of $\mathrm{ZnO}$ (ZD, ZSs, ZS, and ZC) was added. It was followed by magnetic stirring for $1 \mathrm{~h}$ to attain uniform dispersion. The product obtained was collected by centrifugation and repeatedly washed with ethanol to remove the impurities and dried at $85{ }^{\circ} \mathrm{C}$. The illustration is provided in Fig. 2, step II.

\subsection{Characterization}

The X-ray diffraction patterns of the samples were collected on an X-ray powder diffractometer X'Pert Pro Philips using $\mathrm{Cu} \mathrm{K} \alpha$ radiation $(\lambda=1.5406 \AA)$ in the diffraction angle $(2 \theta)$ range between $10^{\circ}$ and $60^{\circ}$. The crystallite size was calculated using the Debye-Scherrer formula $D_{\mathrm{XRD}}=k \lambda / \beta \cos \theta$, where $D_{\mathrm{XRD}}$ is the average crystallite size in $\mathrm{nm}, k$ is the shape factor $(0.9), \lambda$ is the $\mathrm{X}$-ray wavelength in $\mathrm{nm}, \beta$ is the full width at half maximum of the (101) peak in radian and $\theta$ is the Bragg angle (degree). ${ }^{19}$ The lattice parameters of the samples were calculated using the equation $1 / d^{2}=4 / 3\left(1 / a^{2}\right)+1 / c^{2}$, where $d$ is the interplanar distance, and $a$ and $c$ are the lattice parameters in nm (being hexagonal $\left.c / a=(8 / 3)^{1 / 2}\right) \cdot{ }^{20}$ The optical absorption spectra of the samples were recorded over a wavelength range of 200-800 nm using a UV-vis spectrophotometer UV 2401-PC, Shimadzu. Fourier transform infrared spectra (FTIR) of the samples were recorded using an IR Prestige 21 (Shimadzu) spectrophotometer using the $\mathrm{KBr}$ method in the scanning range of 500 to $4000 \mathrm{~cm}^{-1}$. The morphology of the samples was determined by 
using a scanning electron microscope (SEM, ZEISS EVO 18) applying an acceleration voltage of $20 \mathrm{kV}$. The elemental analysis of the samples was performed by the energy dispersive X-ray (EDX) technique equipped with a SEM instrument. Elemental mapping was performed by using an EDX spectroscopic technique associated with a ZEISS EVO 18 instrument. The transmission electron microscopy (TEM) images were collected by using a Tecnai $\mathrm{G}^{2}$ model FEI microscope operating with an accelerating voltage of $300 \mathrm{kV}$. The Brunner-EmmettTeller (BET) surface area of the samples was evaluated on the basis of $\mathrm{N}_{2}$ adsorption-desorption isotherms with a Micromeritics Gemini 2375 Surface Area Analyzer. Prior to the surface area analysis, the samples were degassed for $2 \mathrm{~h}$ at $150{ }^{\circ} \mathrm{C}$.

\subsection{Fabrication of the nonenzymatic electrochemical sensor electrodes}

The nonenzymatic electrochemical sensor electrodes (glassy carbon electrode (GCE)-with $\mathrm{ZnO}$ or $\mathrm{ZnO@1rGO)} \mathrm{have} \mathrm{been}$ prepared by the following procedure. The GCE was first cleaned by polishing with $0.3 \mu \mathrm{m}$ alumina powder. The polished GCE was further processed by ultrasonication for $5 \mathrm{~min}$ each in acetone and double-distilled water, respectively, and dried in ambient air. $1 \mathrm{mg} \mathrm{mL}^{-1}$ of $\mathrm{ZnO}$ or $\mathrm{ZnO@1rGO} \mathrm{was} \mathrm{sonicated} \mathrm{in}$ Nafion for $10 \mathrm{~min}$ to get a uniform dispersion. The cleaned GCE was drop cast with $2 \mu \mathrm{L}$ of $\mathrm{ZnO}$ or $\mathrm{ZnO@1rGO} \mathrm{dispersed} \mathrm{in}$ Nafion. This thin film of the materials deposited on the surface of the electrodes was left overnight at room temperature for drying the deposited material, and the same was used as a working electrode (nonenzymatic electrochemical sensor electrode) for the detection of urea or glucose.

\subsection{Electrochemical studies}

The electrochemical behavior of ZnO (ZD, ZS, ZSs, and ZC) and ZnO@1rGO nanocomposite (ZD@1rGO, ZS@1rGO, ZSs@1rGO, and ZC@1rGO) based electrochemical sensor electrodes has been determined with urea or glucose. Electrochemical experiments, such as cyclic voltammetry (CV) and electrochemical impedance spectroscopy (EIS) analysis, were conducted in a conventional three-electrode cell using an electrochemical work station (VMP3Biologic). The modified glassy carbon electrode (GCE) was used as the working electrode (with a GC disc diameter of $3 \mathrm{~mm}$ ) in combination with a platinum $(\mathrm{Pt}$ ) wire and $\mathrm{Ag} / \mathrm{AgCl}$ (in saturated $\mathrm{KCl})$ as the counter electrode and reference electrode, respectively. $0.1 \mathrm{M}$ potassium ferricyanide solution was used as the electrolyte. All measurements were conducted under ambient conditions. The EIS analysis was performed in $0.1 \mathrm{M}$ potassium ferricyanide solution at a potential of $0.32 \mathrm{~V}$ in the frequency range of $10-10^{6} \mathrm{~Hz}$ at a signal amplitude of $10 \mathrm{mV}$.

\section{Results and discussion}

\subsection{Characterization of rGO prepared via $\mathrm{Zn}$ mediated nascent hydrogen reduction}

Zn dust obtained as a waste by-product from industry was used for the generation of nascent hydrogen for the chemical reduction of GO. The detailed characterization studies of freeze-dried GO prepared via Hummers' method had been reported in our earlier work. ${ }^{18}$ The XRD pattern of the Zn dust is given in Fig. S1 (ESI $\dagger$ ). The characteristic diffraction peaks at $2 \theta$ positions of $36.5^{\circ}, 39.2^{\circ}, 43.4^{\circ}, 54.36^{\circ}, 70.54^{\circ}$, and $70.7^{\circ}$ corresponding to the (002), (100), (101), (102), (103), and (110) lattice planes of pure $\mathrm{Zn}$ metal, respectively (JCPDS file no. 00-004-0831), ${ }^{21}$ confirm the presence of pure $\mathrm{Zn}$ metal in the waste by-product.

The XRD analysis of rGO sheets prepared using nascent hydrogen reduction with $\mathrm{Zn}$ dust is given in Fig. 3A. The XRD pattern of GO is given in the inset of Fig. 3A. The main intensity peak of GO is at $10.8^{\circ}$ corresponding to the (001) reflection plane. After reduction with $\mathrm{Zn}$ dust, this peak completely disappeared, and a new broad diffraction peak centred at $\sim 24.5^{\circ}$ appeared indicating the complete conversion of GO to rGO. This peak corresponds to the (002) plane of rGO nanosheets. ${ }^{22}$ The appearance of a low-intensity peak exhibited by rGO nanosheets at $\sim 44^{\circ}$ corresponds to the (100) reflection plane of rGO. ${ }^{23}$

The UV-vis absorption spectrum of rGO, studied by dispersing rGO nanosheets in DMF, is given in Fig. 3B. The optical properties of GO are also given in the inset of Fig. 3B. The maximum absorption peak of rGO is found to be at $267 \mathrm{~nm}$. During the reduction of GO to rGO, the absorption band corresponding to the aromatic $\mathrm{C}-\mathrm{C}$ bond ( $\pi-\pi^{*}$ transition) is red-shifted from 230 to $267 \mathrm{~nm}$. Hence, the restoration of electronic conjugation and structural ordering in the carbon framework after $\mathrm{Zn}$ mediated hydrogen reduction provides clear evidence for the complete reduction of GO to rGO. ${ }^{16}$

The FTIR spectra obtained for GO and rGO are given in Fig. 3C. In the FTIR spectra of GO we could see a broad absorption band in between 3000 and $3400 \mathrm{~cm}^{-1}$, which corresponds to the $-\mathrm{OH}$ stretching. This peak completely vanishes in the FTIR spectra of rGO. Similarly, a remarkable decrease in the band intensity was observed in the bands corresponding to the stretching of oxygen-containing functionalities such as $\mathrm{C}=\mathrm{O}$ carbonyl $\left(1720 \mathrm{~cm}^{-1}\right)$, epoxy $\mathrm{C}-\mathrm{O}\left(1231 \mathrm{~cm}^{-1}\right),-\mathrm{OH}$ deformation vibrations $\left(1389 \mathrm{~cm}^{-1}\right)$, and alkoxy $\mathrm{C}-\mathrm{O}\left(1043 \mathrm{~cm}^{-1}\right)$ after the nascent hydrogen reduction of GO. ${ }^{16}$

Typical low and high magnification SEM images of rGO are presented in Fig. $4 \mathrm{~A}$ and $\mathrm{B}$, respectively. The fluffy and thin layered nature of rGO nanosheets was confirmed from the SEM images. The microstructure of the rGO nanosheets was again confirmed with the TEM image of rGO, as shown in Fig. 4C.

The probable mechanism for the nascent hydrogen chemical reduction of GO with $\mathrm{Zn}$ dust can be explained as follows: epoxy, carbonyl, and hydroxyl groups are the main oxygen-containing functional groups presented on the GO surface. The homogeneous dispersion of GO in water facilitates the intimate contact between $\mathrm{Zn}$ dust and conc. $\mathrm{HCl}$ thus leading to the in situ generation of nascent hydrogen. This highly reactive nascent hydrogen acts as a reducing agent for the chemical reduction of GO.

$$
\text { Zn dust }+2 \text { conc. } \mathrm{HCl} \rightarrow \mathrm{ZnCl}_{2}+2[\mathrm{H}]
$$



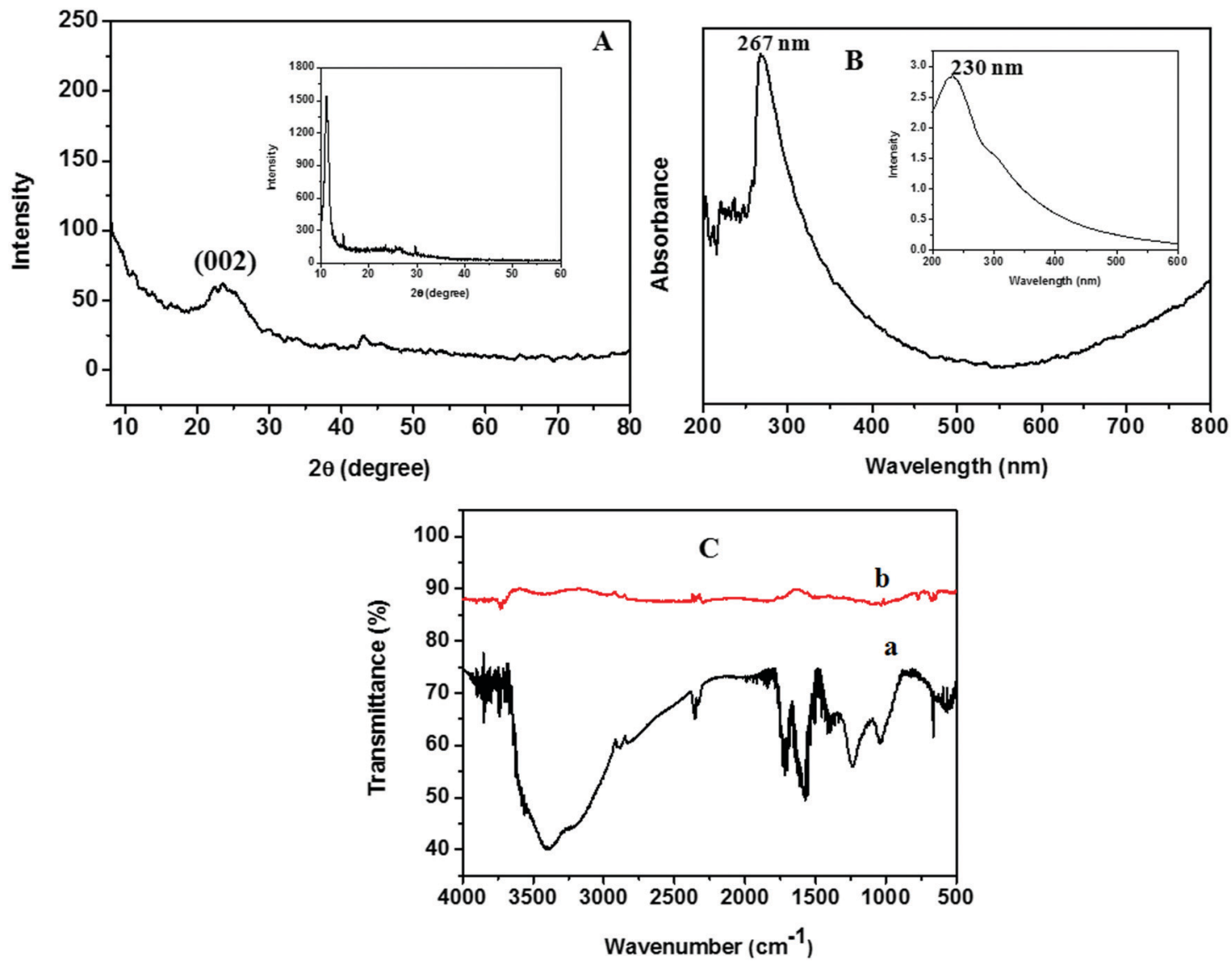

Fig. 3 (A) XRD pattern of $r G O$ prepared using Zn dust. (B) UV-vis spectra of rGO dispersed in DMF. (C) FTIR spectra of (a) GO and (b) rGO. The inset of (A) shows the XRD pattern of $G O$ and the inset of (B) shows the UV-vis spectra of $G O$.
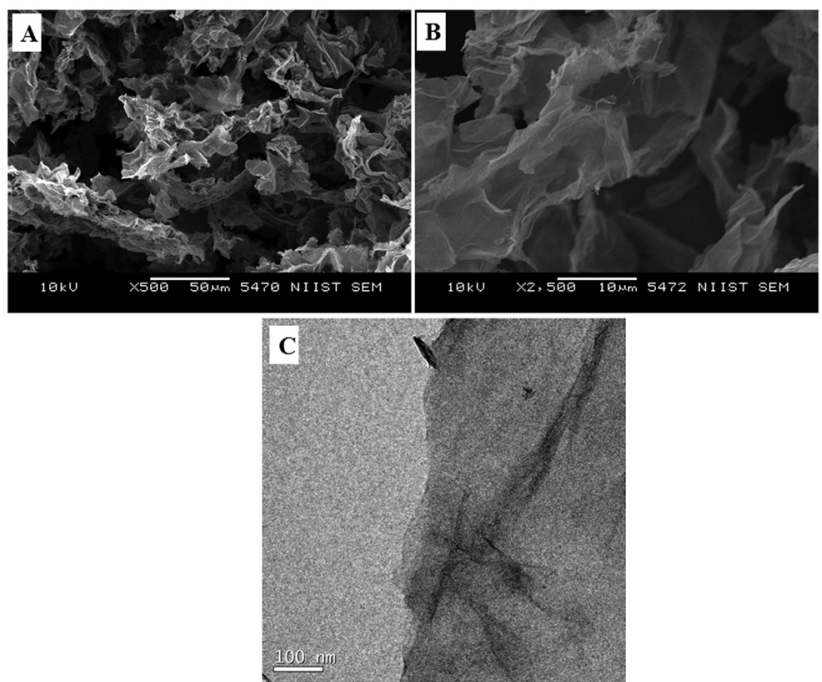

Fig. 4 (A and B) Typical low and high magnification SEM images of rGO prepared via Zn dust mediated nascent hydrogen reduction of GO. (C) TEM image of rGO prepared via chemical reduction with $\mathrm{Zn}$ dust.

The chemical reduction of GO involves the removal of the above mentioned functional groups. It involves the deoxygenation of epoxide groups through the ring-opening mechanism and decarboxylation of carboxylic acid groups. ${ }^{16}$ Both reactions led to the restoration of $\pi$ conjugation $^{14}$ and resulted in olefins. Similarly, carbonyl groups are reduced to the corresponding alcohols, which further give olefins. The conversion of GO to rGO is again clear from the colour change of the reactant mixture from dark brown to black. ${ }^{24}$

The BET surface areas of GO and rGO were measured using $\mathrm{N}_{2}$ adsorption desorption isotherms and are presented in ESI, $\dagger$ Fig. S2. The BET surface areas of GO and rGO are $161 \mathrm{~m}^{2} \mathrm{~g}^{-1}$ and $153 \mathrm{~m}^{2} \mathrm{~g}^{-1}$. During the reduction process there is a chance of agglomeration of the nanosheets and it will result in the decreased surface area of rGO compared to GO.

Electrochemical impedance spectroscopy is a powerful tool for identifying the electrical conductivity of the sensor electrode material. The Nyquist plot of the electrochemical impedance spectra (EIS) of the rGO modified GCE in $0.1 \mathrm{M} \mathrm{K}_{3}\left[\mathrm{Fe}(\mathrm{CN})_{6}\right]$ electrolyte solution is shown in Fig. S3 (ESI $\dagger$ ). An extremely low value of the charge transfer resistance $(250 \mathrm{~m} \Omega)$ of rGO clearly indicates that the material has high electrical conductivity.

\subsection{Characterization of $\mathrm{ZnO}$ nanoparticles prepared via the biotemplate assisted method}

Fig. 5A shows the XRD patterns of pure ZnO synthesized with carbohydrates/cellulose. The XRD pattern indicates that all 

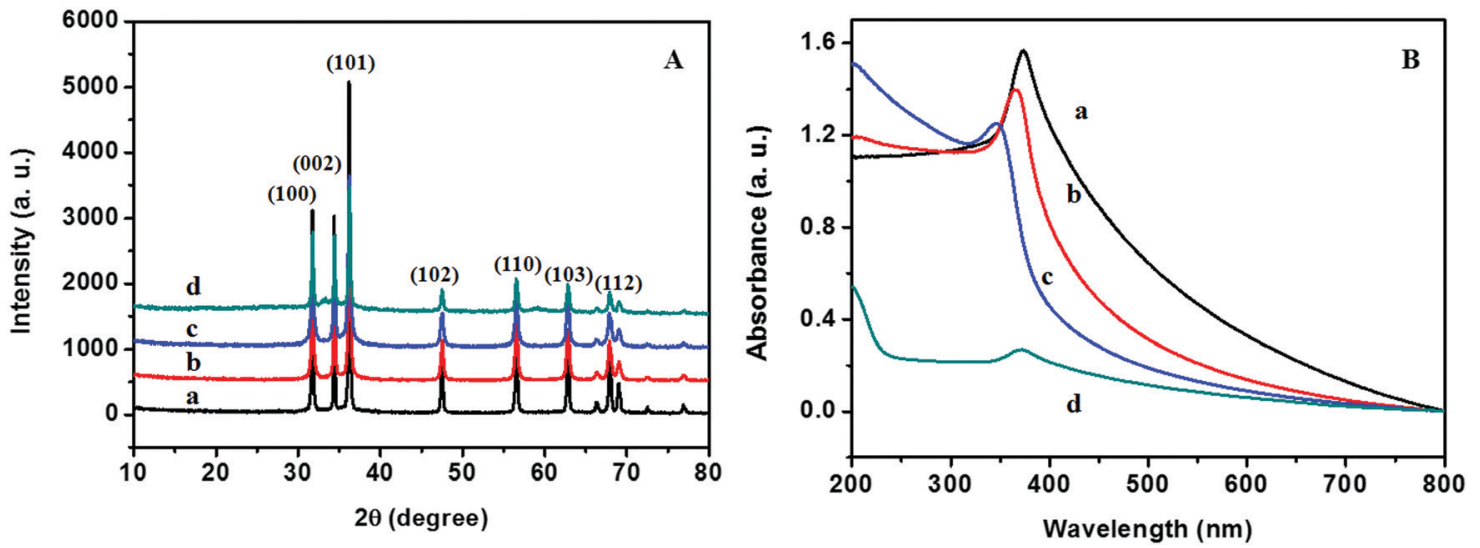

Fig. 5 (A) XRD patterns and (B) UV-vis absorption spectra of (a) ZD, (b) ZS, (c) ZSs, and (d) ZC.

Table 1 Crystallite size $\left(D_{\mathrm{XRD}}\right)$, lattice parameters ( $a$ and $\left.c\right)$, absorption maxima $\left(\lambda_{\max }\right)$, morphology of ZnO nanoarchitectures prepared using different carbohydrates/cellulose

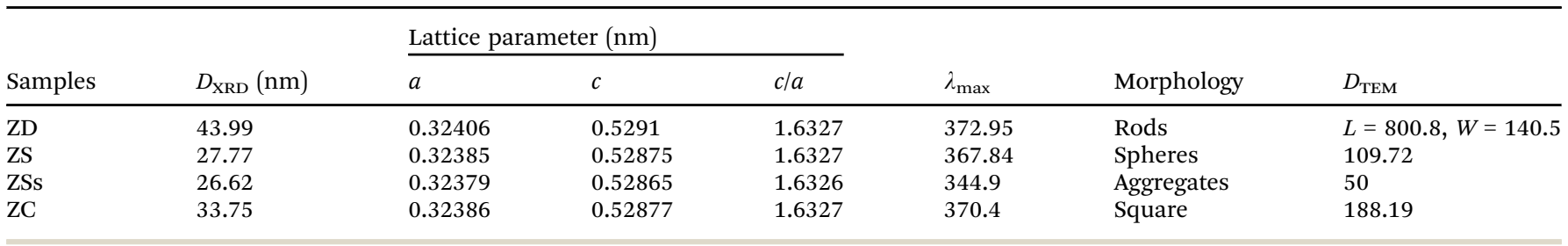

samples are highly crystalline. All of the diffraction peaks of the as-prepared $\mathrm{ZnO}$ nanoarchitectures match well with those of the standard XRD file of ZnO (JCPDS standard card no. 79-0205) and can be indexed as the wurtzite phase of $\mathrm{ZnO}$. The diffraction peaks at $31.7^{\circ}, 34.57^{\circ}, 36.09^{\circ}, 47.53^{\circ}, 56.67^{\circ}, 62.78^{\circ}$, and $67.86^{\circ}$ correspond to the (100), (002) (101), (110), (103), and (112) lattice planes of wurtzite ZnO. No other impurity peaks arising due to carbohydrate/cellulose as well as no remarkable shift in all diffraction peaks were detected in the XRD patterns of the as-prepared samples, which confirm the phase purity of the products. The lattice parameters of the as-prepared samples were calculated and are given in Table 1 . The calculated values of lattice parameters $a=b=0.32379-0.32406 \mathrm{~nm}$ and $c=0.52865-0.5291 \mathrm{~nm}$ are consistent with the reported values of $\mathrm{ZnO}^{25}$ The crystallite size was evaluated using the Scherrer formula and is presented in Table 1. From the Scherrer formula, the crystallite size was estimated to be $\sim 43.99,27.77,26.62$, and $33.75 \mathrm{~nm}$, respectively, for ZD, ZS, ZSs, and ZC.

The optical properties of $\mathrm{ZnO}$ nanoarchitectures synthesized with different carbohydrates/cellulose are studied using UV-vis absorption spectroscopy and are given in Fig. 5B. The maximum absorption peak of ZD is at $372.95 \mathrm{~nm}$. A blueshift in the UV-vis absorption spectra was observed from ZD to ZSs (372.95$344.99 \mathrm{~nm}$ ), which is mainly due to the crystallite size reduction from 43.99 to $26.62 \mathrm{~nm}$. From ZSs to ZC a redshift was observed from 344.9 to $370.4 \mathrm{~nm}$ and is mainly attributed to the increase in the crystallite size from 26.62 to $33.75 \mathrm{~nm}$.

Fig. 6 displays the SEM images of ZnO nanoarchitectures prepared with different carbohydrates/cellulose. ZnO nanoarchitectures (ZD) synthesized with dextrose as a structure-directing

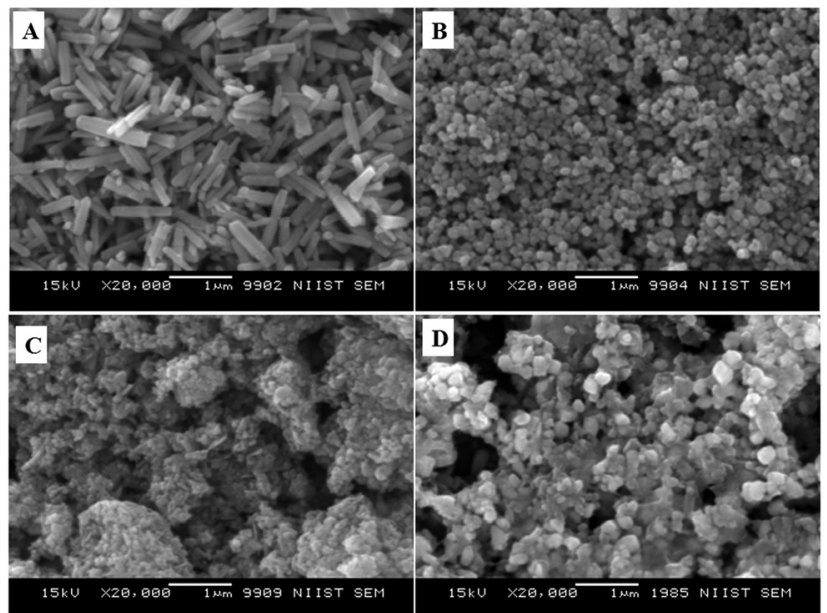

Fig. 6 SEM images of (A) ZD, (B) ZS, (C) ZSs, and (D) ZC.

agent were found to have a rod shape with $\sim 800 \mathrm{~nm}$ length and $\sim 140 \mathrm{~nm}$ width (Fig. 6A). From Fig. 6B, it can be seen that sucrose leads to the formation of $\mathrm{ZnO}$ nanoarchitectures with a diameter of $\sim 91.5 \mathrm{~nm}$. The synthesized $\mathrm{ZnO}$ nanoarchitectures (ZSs) using soluble starch as a structure-directing agent were found to be spherical in shape with smaller particle size (Fig. 6C). But some agglomeration was also observed in this case. Carboxy methyl cellulose leads to the formation of $\mathrm{ZnO}$ nanoarchitectures (ZC) with agglomerates of spherical particles of relatively larger size compared to ZS and ZSs nanoarchitectures (Fig. 6D). Similar observations are obtained in the TEM imaging also. The synthesized ZD nanoarchitectures having a 


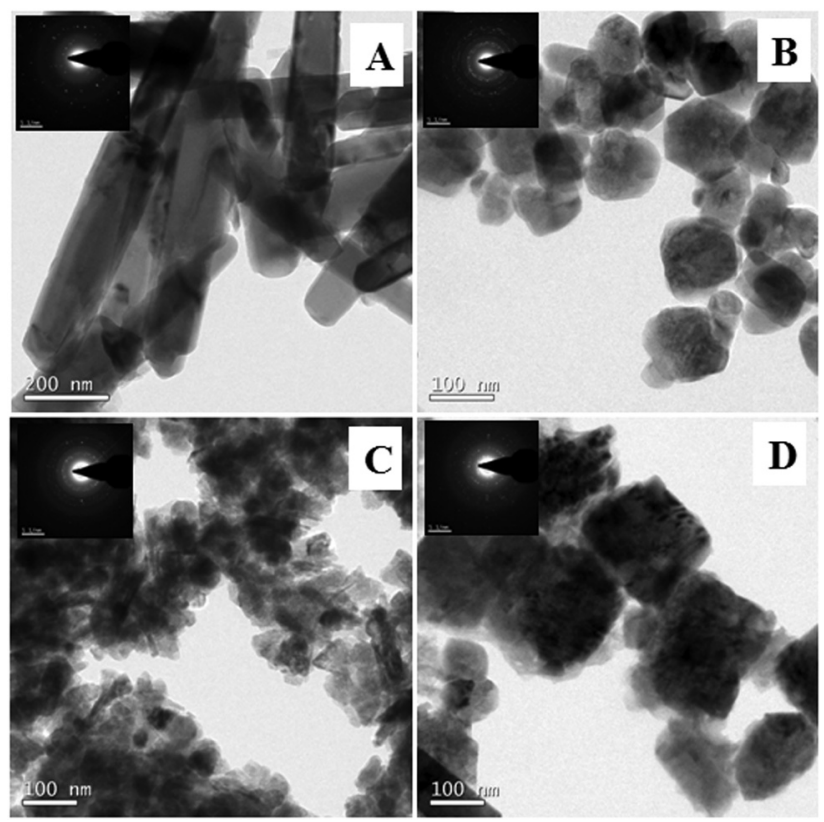

Fig. 7 TEM images of (A) ZD, (B) ZS, (C) ZSs, and (D) ZC.

rod shape with $\sim 800.8 \mathrm{~nm}$ length and $\sim 140.5 \mathrm{~nm}$ diameter (Fig. 7A). The spherical shape of the ZS nanoarchitectures is more clearly seen in the TEM image (Fig. 7B) with a diameter of $\sim 109.72 \mathrm{~nm}$. Soluble starch leads to the formation of $\mathrm{ZnO}$ nanoarchitectures (ZSs) with a relatively small size of $\sim 50 \mathrm{~nm}$. As seen in the SEM image, Fig. 7C also shows uniformly sized agglomerated particles of ZSs nanoarchitectures. Relatively square-shaped particles are observed in the TEM image of ZC with a particle size of $188.19 \mathrm{~nm}$ (Fig. 7D).

\subsection{Characterization of ZnO@1rGO nanocomposites}

The XRD patterns of ZnO@1rGO prepared with different carbohydrates/cellulose are presented in Fig. 8A. All samples show the diffraction patterns of wurtzite $\mathrm{ZnO}$ even in the presence of rGO. The XRD results of all samples show diffraction peaks at $31.77^{\circ}$, $34.31^{\circ}, 36.09^{\circ}, 47.53^{\circ}, 56.67^{\circ}, 62.78^{\circ}$, and $67.6^{\circ}$ corresponding to the lattice planes of (100), (101), (102), (110), (103), and (112). No remarkable shift in the diffraction peaks was observed in the presence of rGO in the nanocomposite. Since the amount of rGO in the nanocomposite is very small, no peaks of rGO were observed in the XRD patterns of nanocomposites. The lattice parameter calculated is listed in Table 2 . The lattice parameter values $(a=0.3232-0.3236 \mathrm{~nm}$, and $c=0.52765-0.52834 \mathrm{~nm})$ are consistent with the reported lattice parameter values of $\mathrm{ZnO}$. The crystallite size evaluated using the Scherrer equation is given in Table 2. The results indicate that the presence of rGO in the nanocomposite did not remarkably affect the crystallite size and lattice parameter of $\mathrm{ZnO}$ nanoarchitectures.

The optical properties of the as-prepared ZnO@1rGO nanocomposites are given in Fig. 8B. We could see a redshift in the absorption spectra of all nanocomposites compared to the spectra of $\mathrm{ZnO}$ nanoarchitectures. The redshift in the $\lambda_{\max }$ values is attributed to the incorporation of rGO in the nanocomposites, and the $\lambda_{\max }$ values are presented in Table 2 .

Fig. 9 shows the SEM images of ZnO@1rGO nanocomposites synthesized with different carbohydrate/cellulose. The insets of Fig. 9B and D show the SEM images at high resolution. The presence of both rGO nanosheets and $\mathrm{ZnO}$ are clearly seen in the SEM images of all samples. It is clear that $\mathrm{ZnO}$ nanoarchitectures are deposited on the surface of rGO sheets. The same observations were again found in the TEM images of ZnO@1rGO (Fig. 10). The SEM and TEM images confirm that the morphology of pure $\mathrm{ZnO}$ is not altered after the preparation of the composite with rGO.

The $\mathrm{N}_{2}$ adsorption-desorption isotherms of $\mathrm{ZnO} @ 1 \mathrm{rGO}$ nanocomposites are shown in Fig. 11. All samples show type IV isotherms. The BET surface areas of ZD@1rGO, ZS@1rGO, ZSs@1rGO, and ZC@1rGO are 6.47, 18.33, 20.03, and $13.21 \mathrm{~m}^{2} \mathrm{~g}^{-1}$. Based on the BET surface area analysis, it is clear that a higher surface area is obtained for the ZSs@1rGO nanocomposite, which is in agreement with the XRD and TEM/SEM results. It is due to the low crystallite size or low particle size shown by the ZSs@1rGO nanocomposite.

The elemental analysis (EDS) spectra of rGO and ZSs@1rGO are presented in Fig. S4 (ESI $\dagger)$. The EDS spectrum of rGO
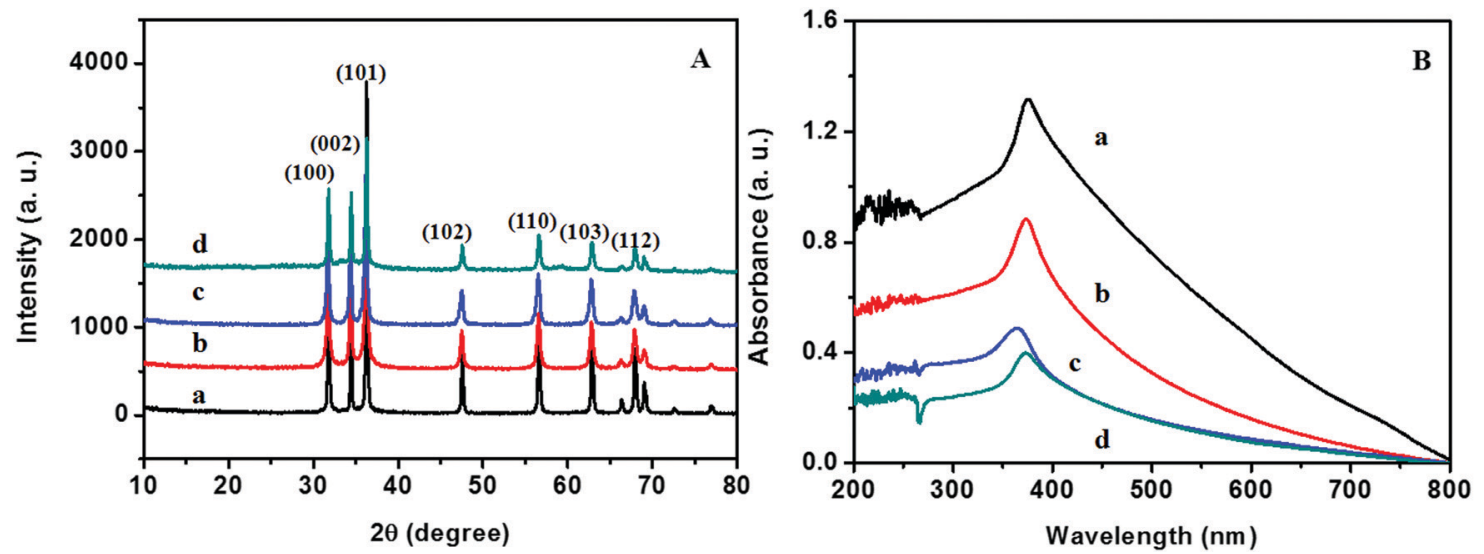

Fig. 8 (A) XRD patterns and (B) UV-vis absorption spectra of (a) ZD@1rGO, (b) ZS@1rGO, (c) ZSs@1rGO, and (d) ZC(a1rGO. 
Table 2 Crystallite size $\left(D_{\mathrm{XRD}}\right)$, lattice parameters ( $a$ and $\left.c\right)$, absorption maxima ( $\left.\lambda_{\max }\right)$, and morphology of ZnO@1rGO samples

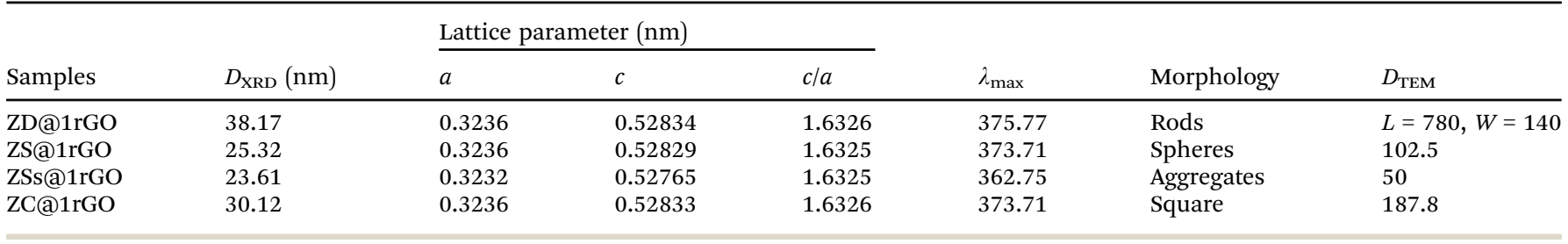
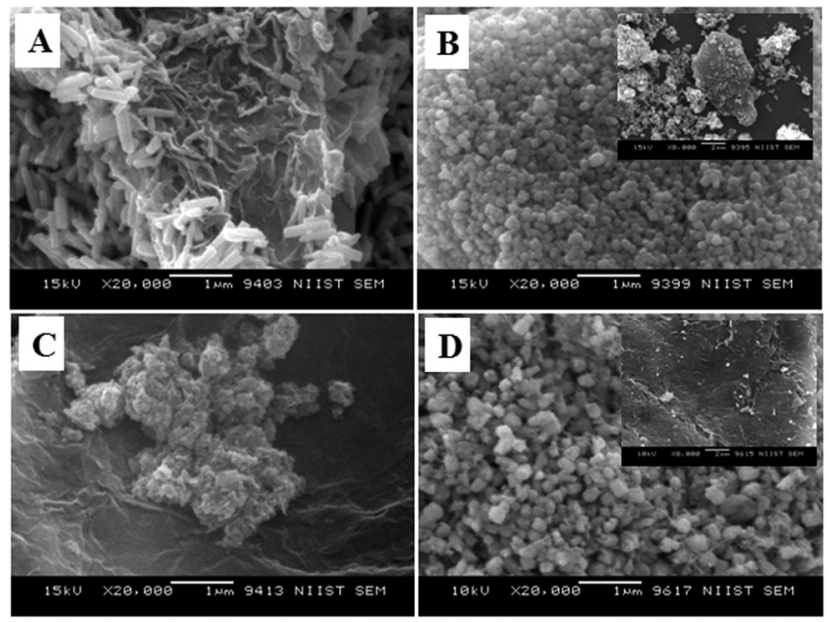

Fig. 9 SEM images of (A) ZD@1rGO, (B) ZS@1rGO, (C) ZSs@1rGO, and (D) ZC@1rGO.

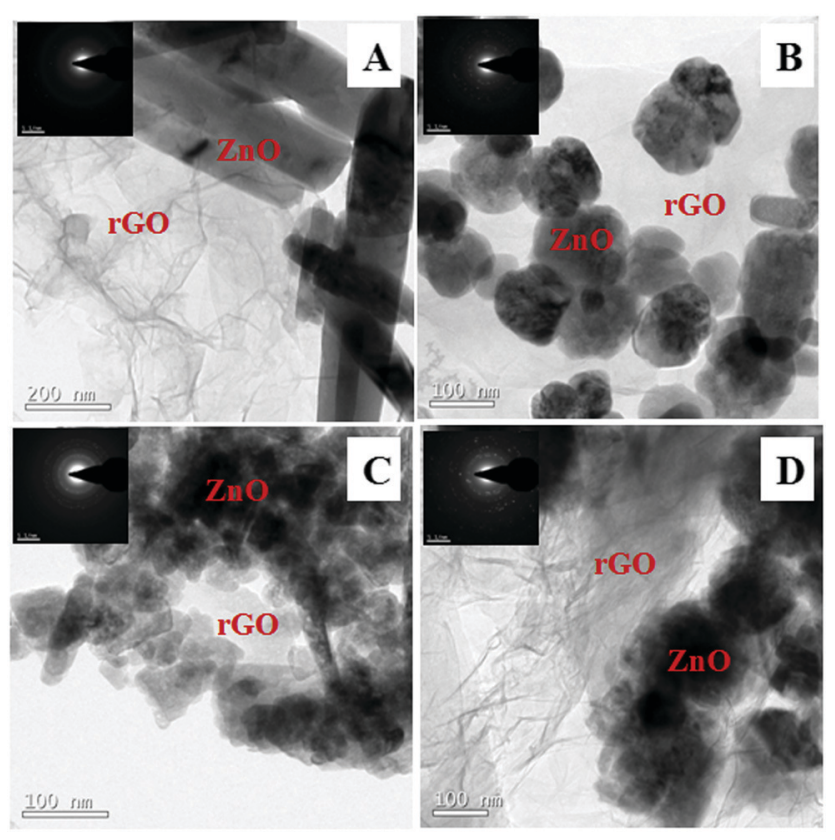

Fig. 10 TEM images of (A) ZD@1rGO, (B) ZS@1rGO, (C) ZSs@1rGO, and (D) ZC@1rGO.

(Fig. S4A, ESI $\dagger$ ) shows the peaks of carbon and oxygen. However, the intensity of oxygen is less compared to carbon in rGO. The presence of $\mathrm{Zn}$ in the nanocomposite is confirmed by the EDS spectrum of ZSs@1rGO. Additional peaks of $\mathrm{C}$ and $\mathrm{O}$

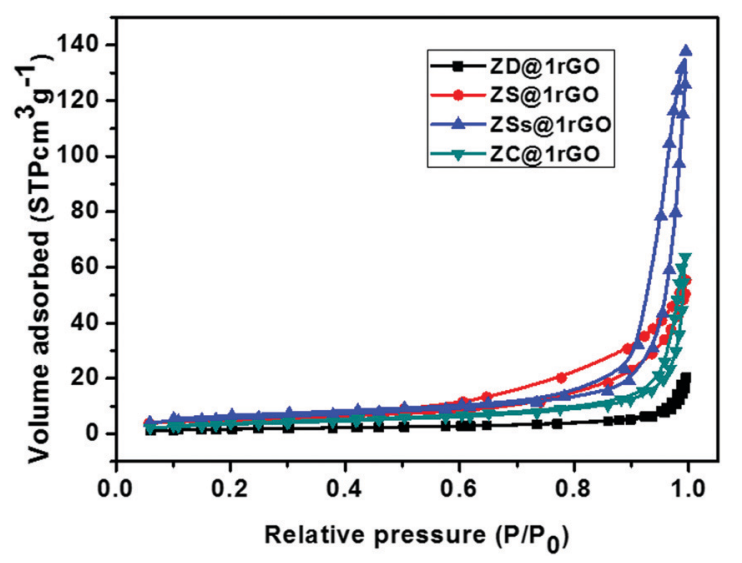

Fig. $11 \mathrm{~N}_{2}$ adsorption-desorption isotherms of $\mathrm{ZnO} @ 1 \mathrm{rGO}$.

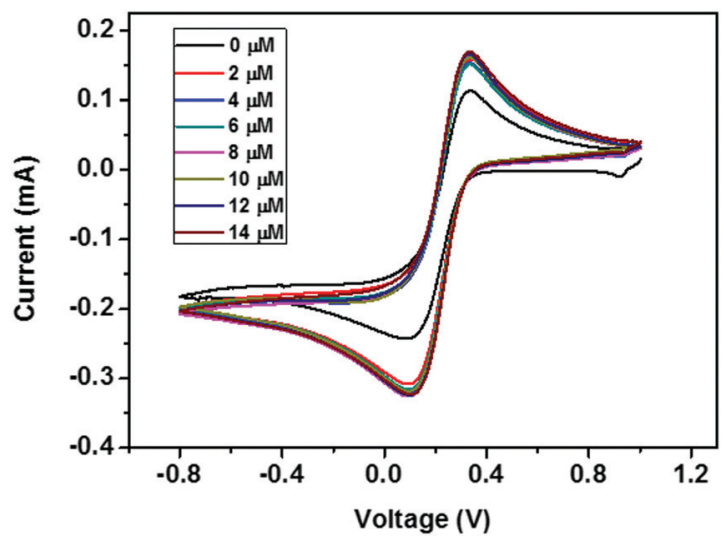

Fig. $12 \mathrm{CV}$ curves of the ZD modified GCE with addition of various concentrations of urea from 0 to $14 \mu \mathrm{M}$.

are also seen in the composite. The elemental mapping of ZSs@1rGO is shown in Fig. S5 (ESI $\dagger$ ). The presence of elements such as $\mathrm{C}, \mathrm{O}$, and $\mathrm{Zn}$ is well mapped in the images.

\subsection{Electrochemical studies}

3.4.1 Electrochemical detection of urea. The electrochemical behavior of the ZD modified GCE towards urea detection was studied with cyclic voltammetry (CV). The CV curve at a scan rate of $50 \mathrm{mV} \mathrm{s}^{-1}$ and potential ranges of -0.8 to $0.8 \mathrm{~V}$ at different urea concentrations from 0 to $14 \mu \mathrm{M}$ is given in Fig. 12. The improvement in the oxidation/reduction peak current after the addition of urea into the electrolyte is very evident from the figure. After the addition of $14 \mu \mathrm{M}$ urea, the oxidation current peak increases from $0.1 \mathrm{~mA}$ to $0.15 \mathrm{~mA}$. 

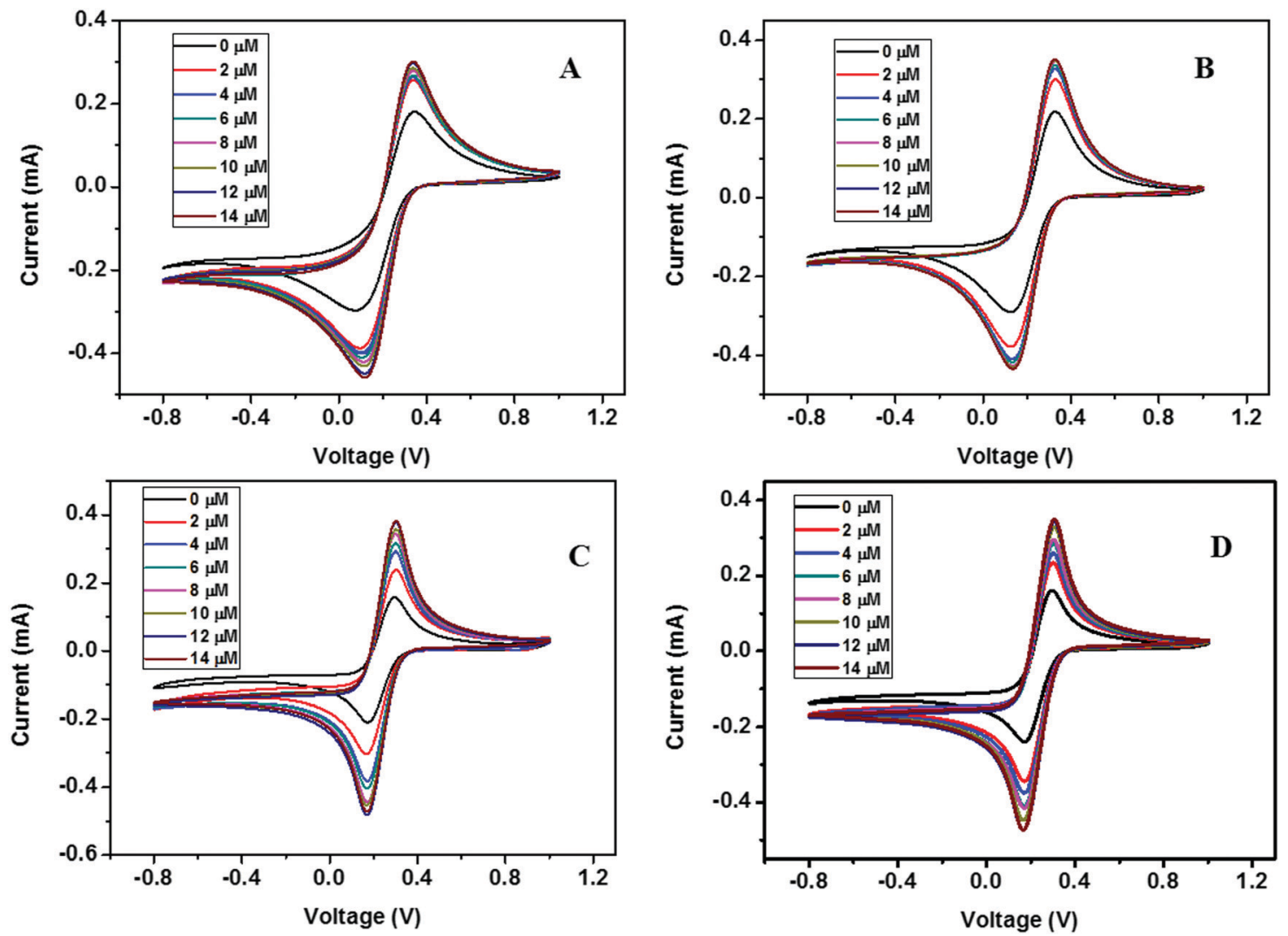

Fig. 13 CV curves of (A) ZD@1rGO, (B) ZS@1rGO, (C) ZSs@1rGO, and (D) ZC@1rGO modified GCEs with the addition of various concentrations of urea from 0 to $14 \mu \mathrm{M}$.

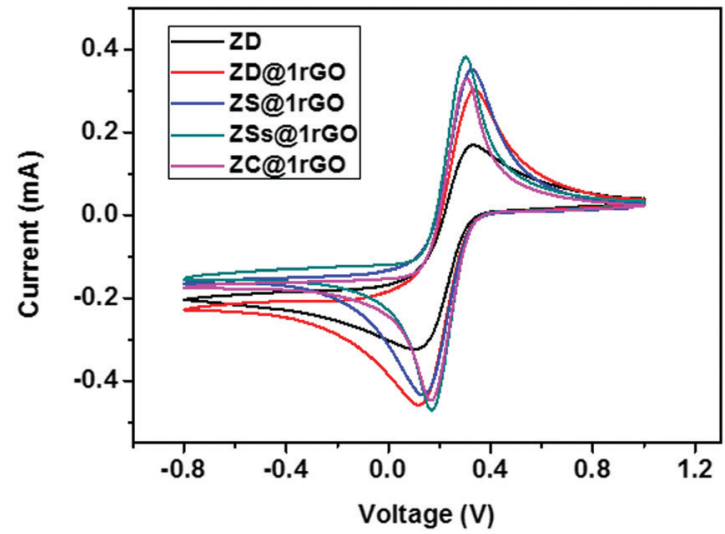

Fig. $14 \mathrm{CV}$ measurements of $\mathrm{ZnO}$ (ZD) and $\mathrm{ZnO}$ (1rGO nanocomposites (ZDa1rGO, ZS@1rGO, ZSs(1rGO, and ZCa1rGO) modified GCEs after the addition of $14 \mu \mathrm{M}$ urea

The cyclic voltammograms of different nanocomposite (ZD@) 1rGO, ZS@1rGO, ZSs@1rGO, and ZC@1rGO) modified GCEs are shown in Fig. 13A-D. In all these cases, oxidation/reduction peak currents increase with the addition of urea into the electrolyte. In the case of the ZSs@1rGO modified GCE, the oxidation current increases from $0.1 \mathrm{~mA}$ to $0.36 \mathrm{~mA}$ (Fig. 13C). The enhancement in the oxidation current was more than double with the ZSs@1rGO nanocomposite modified GCE compared to ZS@1rGO, ZSs@1rGO, and ZC@1rGO modified GCEs after the addition of $14 \mu \mathrm{M}$ urea.

The presence of both $\mathrm{ZnO}$ nanoarchitectures and rGO nanosheets in the nanocomposite results in different architectures on the electrode surface. This will provide a greater active surface, improved immobilization of the target molecules, and a more efficient electron transfer. A comparative study of the CV measurements has been carried out using different nanocomposite modified GC electrodes (ZD@1rGO, ZS@1rGO, ZSs@1rGO, and ZC@1rGO) after the addition of $14 \mu \mathrm{M}$ urea into the electrolyte solution and the results are shown in Fig. 14. The best performance was exhibited by ZSs@1rGO. The higher electrochemical activity of ZSs@1rGO is due to the smaller crystallite size or particle size, as well as, the higher BET surface area of ZSs@1rGO compared to other nanocomposites.

EIS is a commonly used characterization technique to study the impedance changes of the electrode surface, mainly due to the electron transfer between electrolyte and the electrode surface. The Nyquist plot contains a semicircle region and a linear region. The semicircle portion corresponds to the electron transfer limited process, and the linear part corresponds to the diffusion process. The diameter of the semicircle arc is equivalent to the electron transfer resistance $\left(R_{\mathrm{ct}}\right)$, which reflects the conductivity and the electron transfer process. ${ }^{26}$ A large semicircle arc with high $R_{\mathrm{ct}}$ indicates that the system has a higher resistance to the flow of electrons. In Fig. 15A and B the ZnO modified GCE showed a 


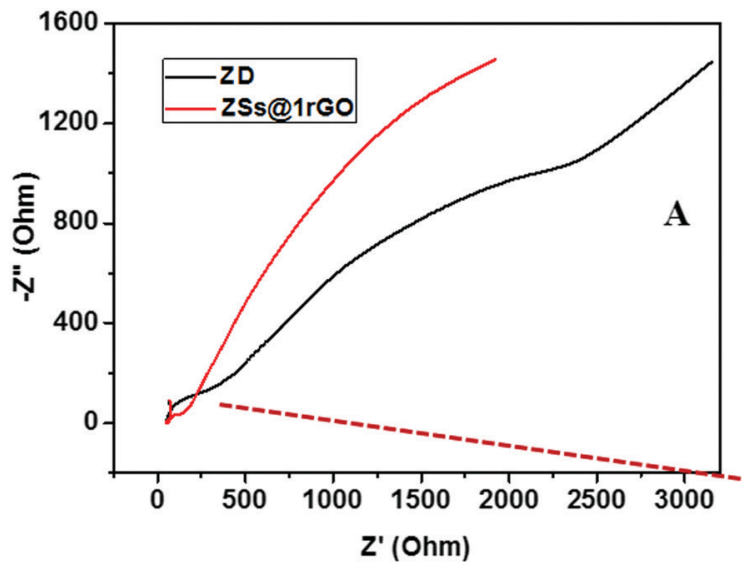

C
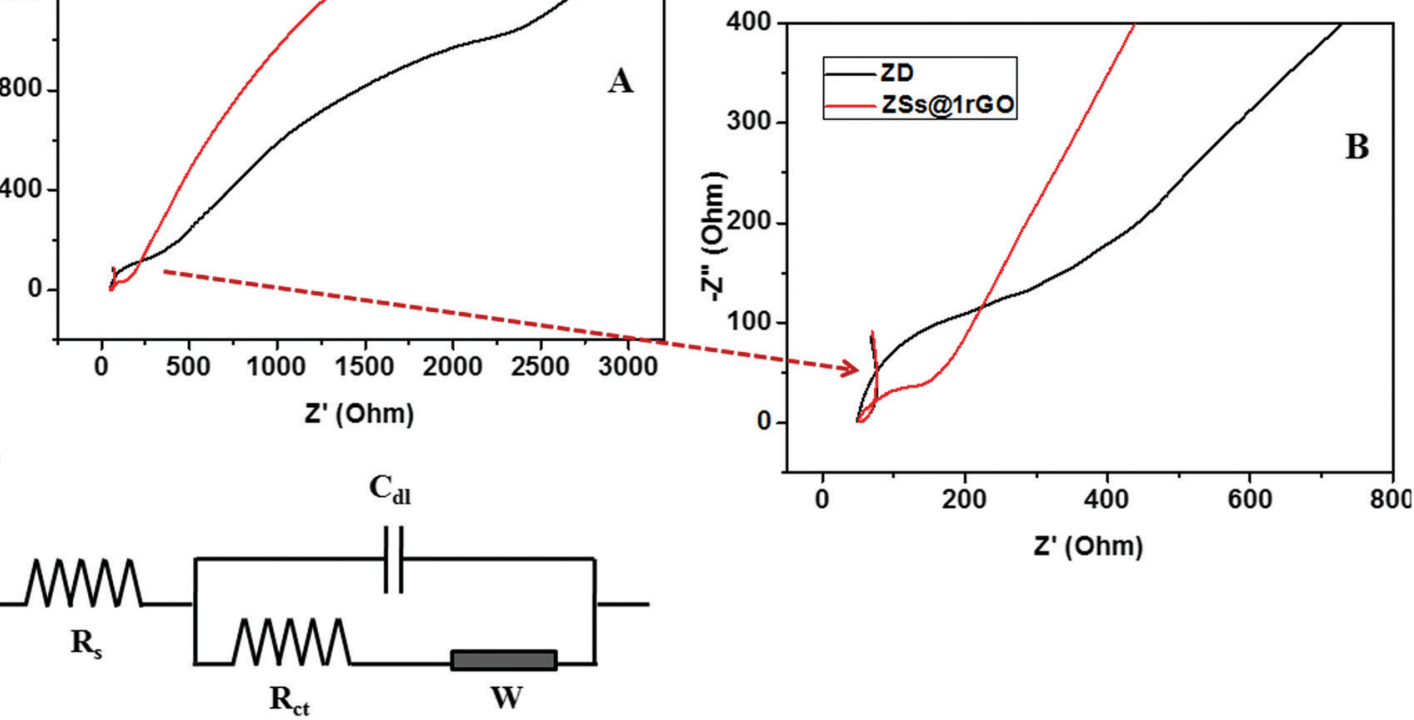

Fig. 15 (A and B) Nyquist diagram of electrochemical impedance spectra of ZD and ZSs(a1rGO modified GCEs in $0.1 \mathrm{M} \mathrm{K} \mathrm{K}_{3}\left[\mathrm{Fe}(\mathrm{CN})_{6}\right]$ electrolyte solution. (C) Randles equivalent circuit.
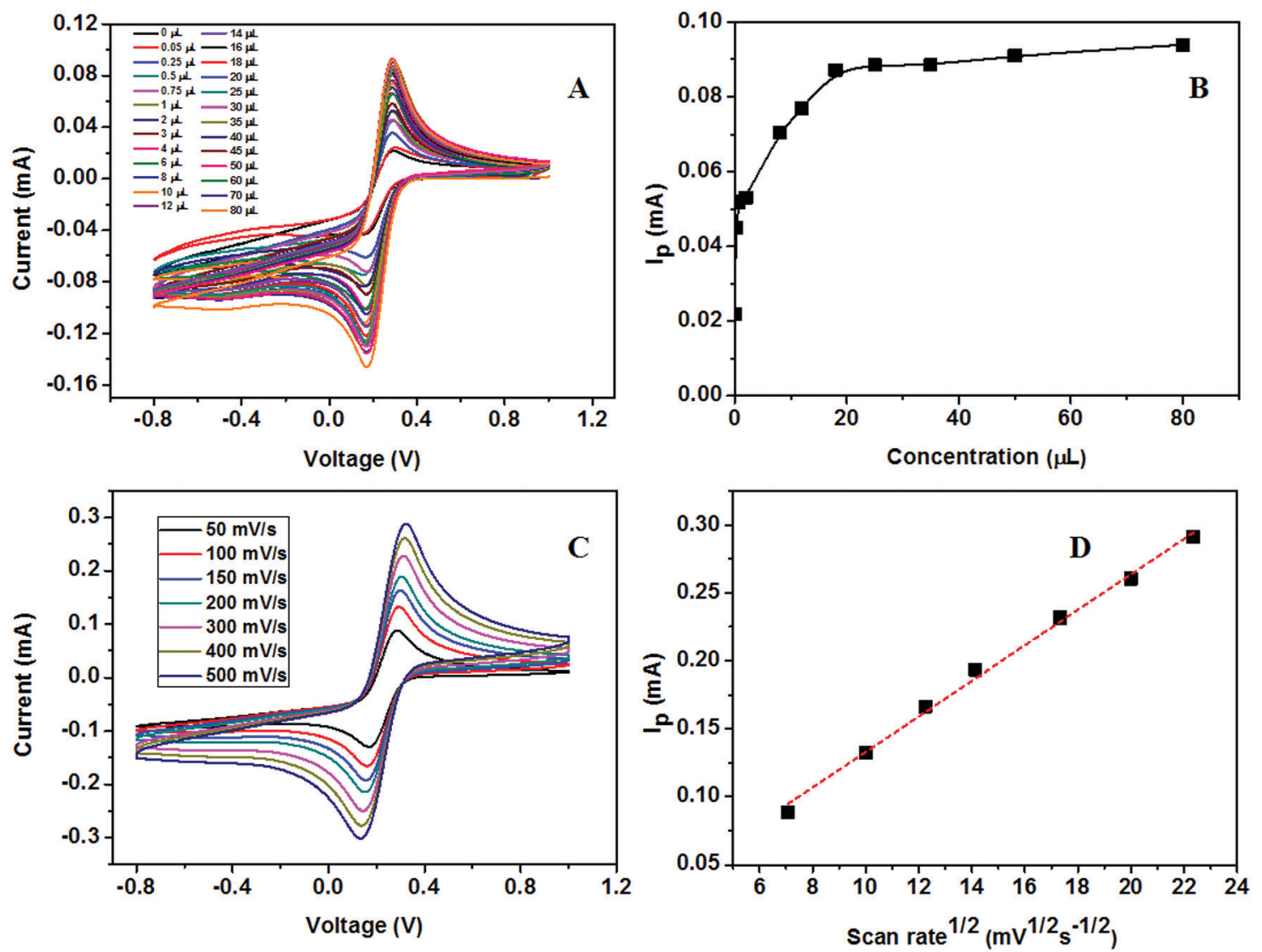

Fig. 16 (A) Calibration study of the ZSs@1rGO modified electrode towards $4 \mathrm{mM}$ urea using CV. (B) Plot of $I_{\mathrm{P}}$ versus concentration. (C) Scan rate study using the ZSs@1rGO modified electrode with different scan rates. (D) Plot of $I_{\mathrm{P}}$ versus square root of scan rate. 
higher $R_{\mathrm{ct}}$ with a larger semicircle diameter $\left(R_{\mathrm{ct}}=169 \Omega\right)$, indicating that $\mathrm{ZnO}$ nanoarchitectures were successfully immobilized on the GCE surface, which hindered the electron transfer of the electrochemical probe. This hindrance was decreased $\left(R_{\mathrm{ct}}=74 \Omega\right)$ after the incorporation of rGO in nanocomposites. The small semicircular diameter of the ZSs@1rGO modified GCE implies that it has low resistance towards the electron transfer process. These results showed the efficiency of the ZSs@1rGO modified GCE compared to the ZnO modified GCE. ${ }^{9,27}$

The calibration study was conducted using CV by the addition of $0.02 \mu \mathrm{M}$ to $32 \mu \mathrm{M}$ urea to the electrolyte solution (Fig. 16A). From the plot of $I_{\mathrm{P}}$ versus concentration of urea given in Fig. 16B, the linear range was calculated and is between $0.02 \times 10^{-3}$ and $7.2 \times 10^{-3} \mathrm{mM}$. The effect of the scan rate for $50,100,150,200,300,400$, and $500 \mathrm{mV} \mathrm{s}^{-1}$ towards the electrochemical oxidation of urea using cyclic voltammetry as the determining mode is shown in Fig. 16C. The oxidation/reduction peak current increases with increasing scan rate. It is evident that the oxidation peak current has a linear dependence on the square root of scan rate (Fig. 16D) compared to $I_{\mathrm{P}}$ versus scan rate. It means that the electrochemical oxidation process is purely diffusion-controlled on the surface of the ZSs@1rGO modified GCE. The lowest detection limit was calculated to be $0.012 \mu \mathrm{M}$, and the sensitivity was found to be $682.8 \mu \mathrm{A} \mathrm{mM} \mathrm{m}^{-1} \mathrm{~cm}^{-2}$. The proposed sensing mechanism for the fabricated urea sensor is described as

$$
\mathrm{CO}\left(\mathrm{NH}_{2}\right)_{2}+8 \mathrm{OH}^{-} \rightarrow 6 \mathrm{H}_{2} \mathrm{O}+\mathrm{CO}_{3}^{2-}+\mathrm{N}_{2}+\mathrm{e}^{-}
$$

3.4.2 Electrochemical detection of glucose. The calibration study was conducted using $\mathrm{CV}$ by the addition of $0.02 \mu \mathrm{M}$ to $160 \mu \mathrm{M}$ glucose (Fig. 17A). The $I_{\mathrm{P}}$ was plotted against concentration (Fig. 17B), and the linear range was calculated to be $0.02 \times 10^{-3}$ to $18 \times 10^{-3} \mathrm{mM}$. The effect of the scan rate on the electrochemical behavior of the ZSs@1rGO modified electrode towards the oxidation of glucose has been conducted using cyclic voltammetry and is shown in Fig. 17C. From the graph it is clear that the oxidation/reduction peak current increases with an increase in the scan rate from $50-500 \mathrm{mV} \mathrm{s}^{-1}$. The linearity of oxidation peak current $\left(I_{\mathrm{P}}\right)$ with the square root of scan rates was observed within the scan rate of $50-500 \mathrm{mV} \mathrm{s}^{-1}$ (Fig. 17D). This indicates that the electrochemical oxidation process is purely diffusion controlled. The lowest detection limit was calculated to be $0.008 \mu \mathrm{M}$, and the sensitivity was found to be $481 \mu \mathrm{A} \mathrm{mM} \mathrm{mm}^{-1} \mathrm{~cm}^{-2}$.

The proposed sensing mechanism for the fabricated glucose sensor is described as

$$
\mathrm{O}_{2} \mathrm{~g} \text { (air/liquid interface) } \leftrightarrow \mathrm{O}_{2} \text { ads (ZnO@rGO) }
$$
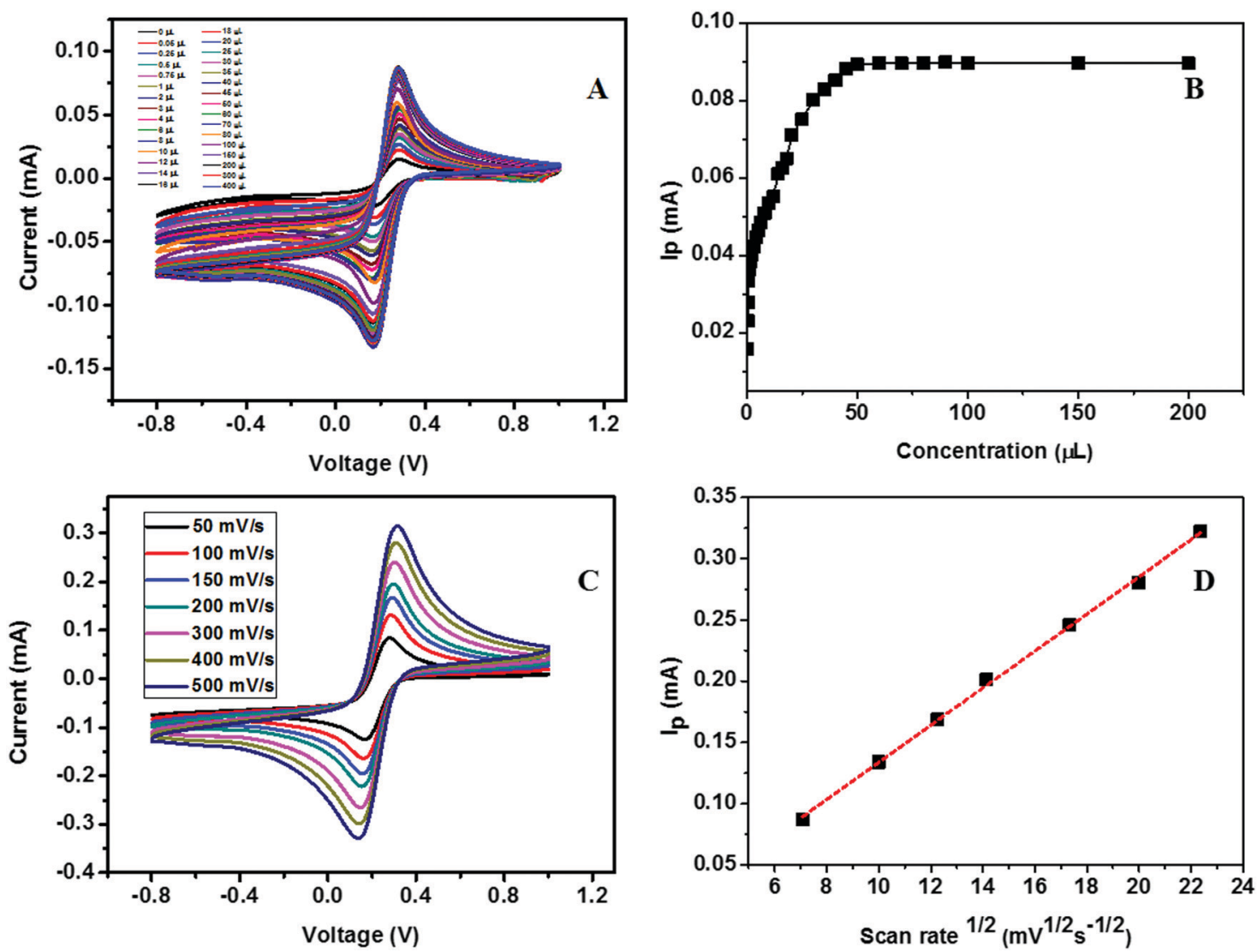

Fig. 17 (A) Calibration study of the ZSs@1rGO modified electrode towards $4 \mathrm{mM}$ glucose. (B) Plot of $I_{\mathrm{P}}$ versus concentration. (C) Scan rate study using the ZSs@1rGO modified electrode with different scan rates. (D) Plot of $I_{\mathrm{P}}$ versus square root of scan rate. 
Table 3 Comparison of the sensing characteristics of the developed urea and glucose sensors using ZSs@1rGO with the other nonenzymatic sensors

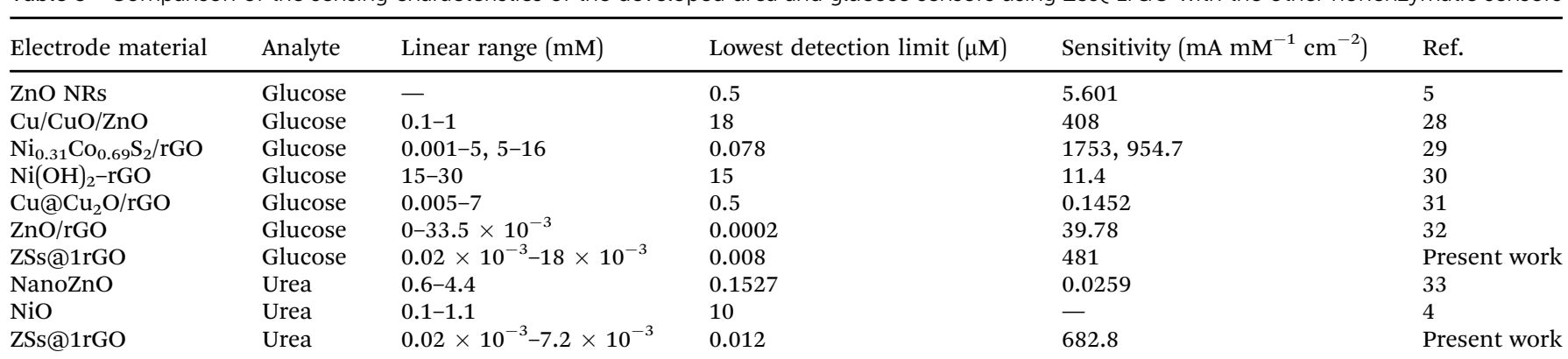

$$
\begin{gathered}
\mathrm{O}_{2} \text { ads }(\mathrm{ZnO})+2 \mathrm{e}^{-}(\mathrm{ZnO} @ \mathrm{rGO}) \leftrightarrow 2 \mathrm{O}^{-} \text {ads }\left(\mathrm{O}^{-} / \mathrm{O}_{2}{ }^{-}\right) \\
\text {Glucose }+\mathrm{O}^{-} \text {glucono- } \rightarrow \delta \text {-lactone }+2 \mathrm{e}^{-} \\
\text {Glucono- } \delta \text {-lacone } \rightarrow \text { gluconic acid }
\end{gathered}
$$

The present study confirms that the ZnO nanoarchitectures act an efficient electron mediator for the fabrication of efficient nonenzymatic sensor.

The results obtained in the present study are compared with the literature data on similar types of nonenzymatic sensors for detecting urea or glucose. The comparison shown in Table 3 reveals that the fabricated urea and glucose sensor based on the ZSs@1rGO modified GCE is highly effective in the accurate detection of urea and glucose. The developed ZSs@1rGO modified GCE has shown the lowest detection $(0.008 \mu \mathrm{M}$ for glucose and $0.012 \mu \mathrm{M}$ for urea) and excellent sensitivity (481 $\mathrm{mA} \mathrm{mM} \mathrm{mM}^{-1} \mathrm{~cm}^{-2}$ for glucose and $682.8 \mathrm{~mA} \mathrm{mM}^{-1} \mathrm{~cm}^{-2}$ for urea) in the concentration range of $0.02 \times 10^{-3}-18 \times$ $10^{-3} \mu \mathrm{M}$ for glucose and of $0.02 \times 10^{-3}-7.2 \times 10^{-3} \mu \mathrm{M}$ for urea.

Interference study of rGO based metal oxides is well established. From the literature it was observed that in the case of $\mathrm{CeO}_{2} / \mathrm{rGO}$ or $\mathrm{AgFe}_{2} \mathrm{O}_{3} / \mathrm{rGO}$ modified GCEs, the presence of biological interfering species show no significant effect on the peak current. ${ }^{34,35}$ The reported studies say that a similar observation will be obtained with AA, UA, $\mathrm{H}_{2} \mathrm{O}_{2}$ and DA.

\section{Conclusions}

In the present work, the as-prepared GO was reduced with a nascent hydrogen reduction mechanism using metallic zinc obtained as a waste by-product from industry. The formed rGO was then analyzed with XRD, UV-vis, SEM, and TEM. The peak shift from 10.8 to $24.5^{\circ}$ in the XRD pattern and the redshift in the UV-vis absorption spectra from 230 to $267 \mathrm{~nm}$ confirm the complete reduction of GO to rGO. In addition to this, $\mathrm{ZnO}$ nanoarchitectures with various morphologies were prepared using carbohydrate/cellulose as a bio-template. The as-prepared ZnO nanoarchitectures were used to decorate rGO sheets, which results in a ZnO@rGO nanocomposite. Due to the synergistic effect of $\mathrm{ZnO}$ and rGO, the prepared $\mathrm{ZnO} @$ rGO nanocomposite was found to be an excellent probe for the nonenzymatic electrochemical sensing of urea and glucose. The electrochemical studies revealed that the fabricated electrode was sensitive to urea in the concentration range of $0.02 \times 10^{-3}-7.2 \times 10^{-3} \mathrm{mM}$ with a detection limit of $0.012 \mu \mathrm{M}$. The developed nonenzymatic sensor electrode was sensitive to glucose in the concentration range of $0.02 \times 10^{-3}-18 \times 10^{-3} \mathrm{mM}$ with a detection limit of $0.008 \mu \mathrm{M}$. The developed sensor exhibited an ultra-high sensitivity of $682.8 \mu \mathrm{A} \mathrm{mM} \mathrm{mm}^{-1} \mathrm{~cm}^{-2}$ towards urea and $481 \mu \mathrm{A} \mathrm{mM} \mathrm{mm}^{-1} \mathrm{~cm}^{-2}$ towards glucose.

\section{Conflicts of interest}

There are no conflicts to declare.

\section{Acknowledgements}

We gratefully acknowledge the Director, CSIR-National Institute of Science and technology (NIIST), for providing the laboratory facilities to carry out the experiments. K. B. Babitha is thankful to CSIR, India, for providing the Senior Research Fellowship (SRF). R. B. Rakhi is thankful to DST-SERB for the Ramanujan Fellowship (SB/S2/RJN-098/2015). The authors also thank $\mathrm{M} / \mathrm{s}$ Binani Zinc Limited for the zinc dust which was used in the reduction of GO. The authors also thank Mr Prithviraj for XRD, Mr Kiran Mohan for TEM, Mrs Soumya and Mr V. Harish Raj for SEM, and Mr George for FTIR analysis. All the members of the Materials Science and Technology Division are acknowledged for providing general support.

\section{References}

1 D. Dutta, S. Chandra, A. K. Swain and D. Bahadur, Anal. Chem., 2014, 86, 5914-5921.

2 R. C. Bianchi, E. R. D. Silva, L. H. Dall'Antonia, F. F. Ferreira and W. A. Alves, Langmuir, 2014, 30, 11464-11473.

3 O. O. Soldatkin, I. S. Kucherenko, S. V. Marchenko, K. B. Ozansoy, B. Akata, A. P. Soldatkin and S. V. Dzyadevych, Mater. Sci. Eng., C, 2014, 42, 155-160.

4 M. Arain, A. Nafady, Sirajuddin, Z. H. Ibupoto, S. T. H. Sherazi, T. Shaikh, H. Khan, A. Alsalme, A. Niaz and M. Willander, RSC Adv., 2016, 6, 39001-39006.

5 G. N. Dar, A. Umar, S. A. Zaidi, S. Baskoutas, S. H. Kim, M. Abaker, A. Al-Hajry and S. A. Al-Sayari, Sci. Adv. Mater., 2011, 3, 901-906.

6 C. Chen, Q. Xie, D. Yang, H. Xiao, Y. Fu, Y. Tan and S. Yao, RSC Adv., 2013, 3, 4473-4491. 
7 V. K. L. Shanbhag and K. S. Prasad, Anal. Methods, 2016, 8, 6255-6259.

8 T. R. Kumar, K. J. Babu, D. J. Yoo, A. R. Kim and G. G. Kumar, RSC Adv., 2015, 5, 41457-41467.

9 J. Jiang, P. Zhang, Y. Liua and H. Luo, Anal. Methods, 2017, 9, 2205-2210.

10 P. T. Yin, T. H. Kim, J. W. Choi and K. B. Lee, Phys. Chem. Chem. Phys., 2013, 15, 12785-12799.

11 Y. Zhao, L. Fan, B. Hong, J. Ren, M. Zhanga, Q. Queb and J. Jib, Sens. Actuators, B, 2016, 231, 800-810.

12 X. Gao, J. Jang and S. Nagase, J. Phys. Chem. C, 2010, 114, 832-842.

13 P. Cui, J. Lee, E. Hwang and H. Lee, Chem. Commun., 2011, 47, 12370-12372.

14 V. H. Pham, H. D. Pham, T. T. Dang, S. H. Hur, E. J. Kim, B. S. Kong, S. Kim and J. S. Chung, J. Mater. Chem., 2012, 22, 10530-10536.

15 O. Akhavan, E. Ghaderi, S. Aghayee, Y. Fereydoonia and A. Talebia, J. Mater. Chem., 2012, 22, 13773-13781.

16 R. S. Dey, S. Hajra, R. K. Sahu, C. R. Raj and M. K. Panigrahic, Chem. Commun., 2012, 48, 1787-1789.

17 M. B. M. Krishna, N. Venkatramaiah, R. Venkatesan and D. Narayana Rao, J. Mater. Chem., 2012, 22, 3059-3068.

18 K. B. Babitha, S. Nishanth Kumar, V. Pooja, B. S. Dileep Kumar, A. Peer Mohamed and S. Ananthakumar, Chem. Eng. J., 2017, 324, 154-167.

19 K. B. Jaimy, K. V. Baiju, S. K. Ghosh and K. G. K. Warrier, J. Solid State Chem., 2012, 186, 149-157.

20 K. Jayanthi, S. Chawla, A. G. Joshi, Z. H. Khan and R. K. Kotnala, J. Phys. Chem. C, 2010, 114, 18429-18434.
21 S. Balanand, K. B. Babitha, M. Jeen Maria, A. A. PeerMohamed and S. Ananthakumar, ACS Sustainable Chem. Eng., 2018, 6, 143-154.

22 M. S. A. S. Shah, A. R. Park, K. Zhang, J. H. Park and P. J. Yoo, ACS Appl. Mater. Interfaces, 2012, 4, 3893-3901.

23 T. Lv, L. Pan, X. Liu and Z. Sun, Catal. Sci. Technol., 2012, 2, 2297-2301.

24 C. K. Chua and M. Pumera, Chem. Soc. Rev., 2014, 43, 291-312.

25 D. Pradhan and K. T. Leung, Langmuir, 2008, 24, 9707-9716.

26 K. S. Bhat and H. S. Nagaraja, Mater. Res. Innovations, 2019, $1-24$.

27 R. M. Shereema, S. R. Nambiar, S. S. Shankar and T. P. Rao, Anal. Methods, 2015, 7, 4912-4918.

28 S. SoYoon, A. Ramadoss, B. Saravanakumar and S. J. Kim, J. Electroanal. Chem., 2014, 717-718, 90-95.

29 G. Li, H. Huo and C. Xu, J. Mater. Chem. A, 2015, 3, 4922-4930.

30 P. Subramanian, J. Niedziolka-Jonsson, A. Lesniewski, Q. Wang, M. Li, R. Boukherroub and S. Szunerits, J. Mater. Chem. A, 2014, 2, 5525-5533.

31 H. Huo, C. Guo, G. Li, X. Han and C. Xu, RSC Adv., 2014, 4, 20459-20465.

32 M. Sreejesh, S. Dhanush, F. Rossignol and H. S. Nagaraja, Ceram. Int., 2017, 43, 4895-4903.

33 A. Ali, A. A. Ansari, A. Kaushik, P. R. Solanki, A. Barik, M. K. Pandey and B. D. Malhotra, Mater. Lett., 2009, 63, 2473-2475.

34 A. A. Ensafi, R. Noroozi, N. Z. Atashbar and B. Rezaei, Sens. Actuators, B, 2017, 245, 980-987.

35 N. Zhang and J. Zheng, J. Mater. Sci.: Mater. Electron., 2017, 28, 11209-11216. 